\title{
ATP assay for rapid onboard testing to detect living microorganisms in Ballast Water
}

Seungshic Yum ${ }^{a}$, Bong Gil Hyun ${ }^{b}$, Kitae Rhie ${ }^{c}$, Kyoungsoon Shin ${ }^{b}$

aSouth Sea Environment Research Center, Korea Institute of Ocean Science and Technology, Goeje 53201, Republic of Korea

ballast Water Center, Korea Institute of Ocean Science and Technology, Goeje 53201, Republic of Korea

'Department of Biology, Kyung Hee University, Seoul 02447, Republic of Korea

\section{ABSTRACT}

Rapid and simple analytical methods for viable microorganism detection in ballast water are required to evaluate the efficiency of ballast water treatment system. During the course of systematic investigation of the cytotoxicity and apoptosis assays, it was found that the adenosine triphosphate (ATP) and luminescence based cell viability assay, in other word, an ATP assay was the most sensitive and applicable to ballast water management (BWM). The assay was applied to cultured microalgae samples, and it could detect the existence of 5 viable cells in $100 \mu \mathrm{l}$. Comparably low luminescent values were detected in two cultured diatom species than in cultured dinoflagellates. This result might be caused by the small cell volume in diatom species. Following a regression model between ATP concentration and cell volume, an ATP guideline (876 - 109246 relative luminescence units: RLU) was developed for the evaluation of treated ballast water. ATP assay was also applied to the evaluation of ballast water treatment system (BWTS). The luminescence value which obtained from the ATP assay also showed a good correlation with the presence of living natural plankton cells with comparably low luminescence values than the cultured species. The low ATP concentration in natural plankton cells may reflect a decline in their biological activity because of extended exposure to dark conditions. ATP assay could be a suitable method for the monitoring of ballast water management compliance even though the results of this study need further validation.

Keywords: Ballast water management system (BWMS), Adenosine triphosphate (ATP), Relative luminescence units (RLU), ballast water management compliance

\section{Introduction}

Adenosine triphosphate (ATP) is the main energy carrier molecule in all living organisms. Consequently, quantitating the amount of ATP present can indicate the number of viable singlecelled organisms, because ATP indicates the presence of metabolically active cells. In addition, ATP analyses can be completed in $<1 \mathrm{~h}$, and the equipment needed is simple to operate. Therefore, an ATP bioluminescence-based method has recently been recommended as a prospective tool for vessel on board indicative analysis.

\section{Materials and Methods}

\section{ATP assay}

ATP concentration was measured using a Glomax Microplate Luminometer in combination with the CellTiter-Glo 2.0 Assay (Promega).

\section{Laboratory experiment}

ATP assay was carried out in two diatoms, five dinoflagellates and one Chrysophyceae cultures of the phytoplankton (see Fig. 1). 


\section{Full scale land-based test}

Analyses for living organisms and the ATP concentration were carried out to determine the relationship between the parameters in two land-based tests, one involving brackish water (salinity approximately $19 \mathrm{ppt)}$ and other involving seawater (salinity approximately $30 \mathrm{ppt}$ ). The number of living organisms in each sample was determined in triplicate, and the ATP concentration was measured in triplicate or duplicate.

\section{Results}

\section{Linearity between cultured phytoplankton species and the $R L U$ value}

In this study the ATP assay was conducted using samples having low cell concentrations, and $\mathrm{RLU}$ signals were detected at concentrations $<5$ cells $0.1 \mathrm{ml}^{-1}$ for all species studied (Figure 1).

Figure1. Relationship between the RLU signal and the cell concentration for each cultured species.
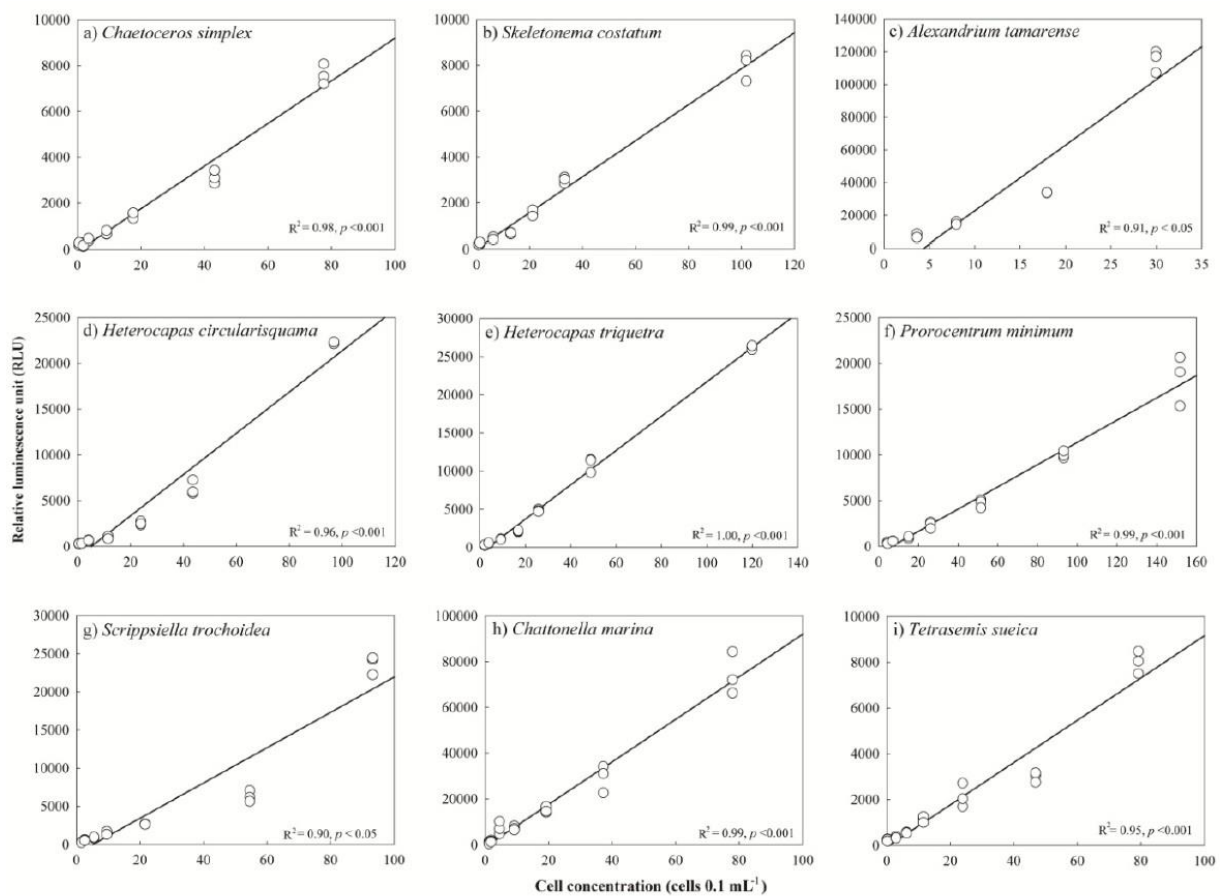

\section{Application of ATP assay for full scale land-based test}

Consistent with the microscopy data, the greatest reduction in the RLU signal was also observed between the control and treated samples (>90\%; $P>0.05)$ except discharge treated in seawater $(68 \%$ reduction, $P=0.06)$ (Figure 2$)$. Low treatment efficiency was evident in seawater discharge samples, through the higher RLU levels detected in these compared with other uptake and discharge treated samples (Figure 2). It may be that small phytoplankton (< $10 \mu \mathrm{m}$ ) and bacteria were not killed during disinfection, and could produce a RLU signal similar to that from small numbers of large cells. 
Figure 2. Difference in the RLU signal between the control and treated water during the full scale land-based tests using brackish water and seawater. Values and error bars represent the mean and standard deviation $(n>3)$, respectively, for all tests performed. $t$-test significance: ${ }^{* *}: P<0.01 ;{ }^{* *}: P<0.001$.

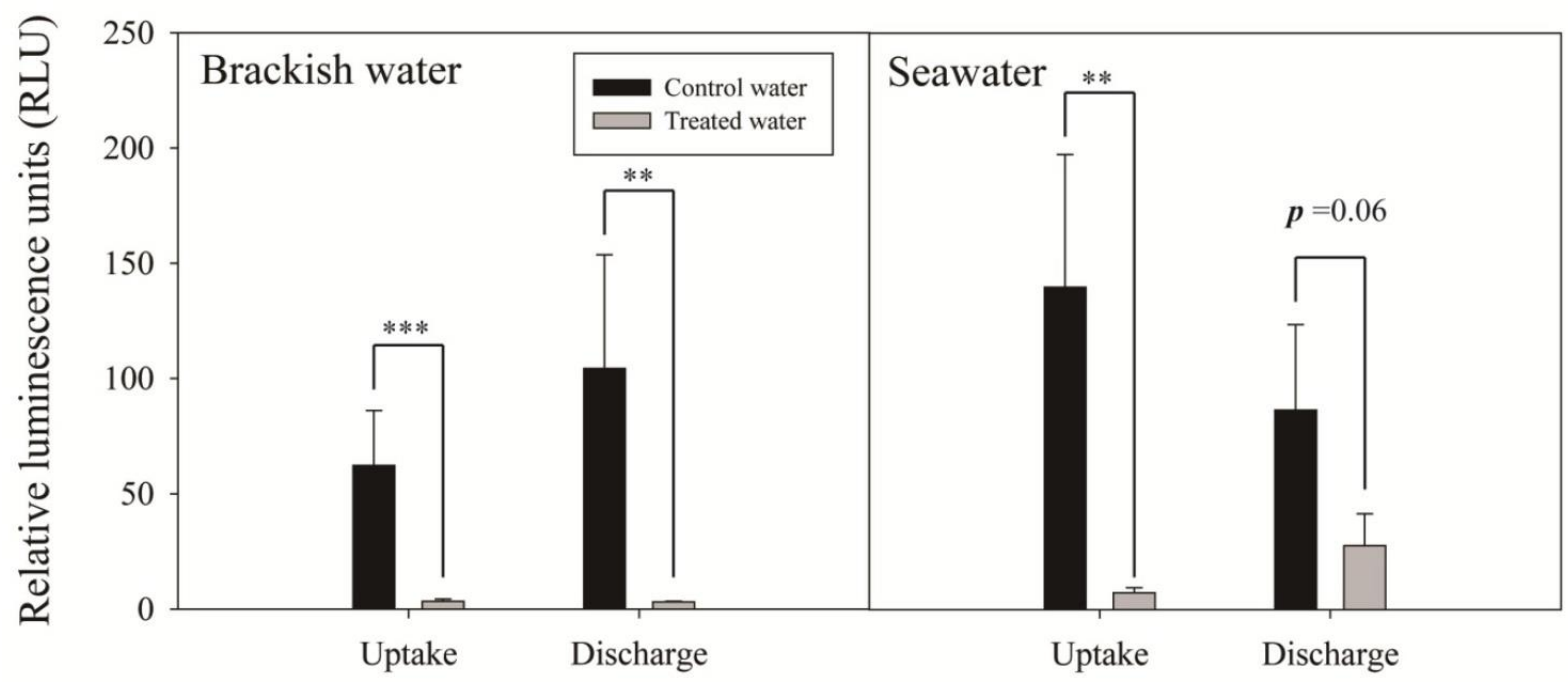

